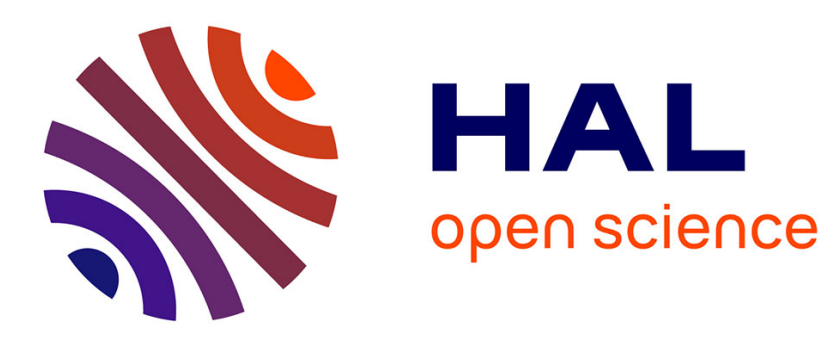

\title{
Using Equivalent Emission Sources to Evaluate the Coupling between Components
}

\author{
Sanaa Zangui, Kévin Berger, Ronan Perrussel, Edith Clavel, Carlos Antonio \\ França Sartori, Christian Vollaire
}

\section{- To cite this version:}

Sanaa Zangui, Kévin Berger, Ronan Perrussel, Edith Clavel, Carlos Antonio França Sartori, et al.. Using Equivalent Emission Sources to Evaluate the Coupling between Components. Compumag 2011, Jul 2011, Sydney, Australia. pp.682-683, id. 424. hal-00605918

\section{HAL Id: hal-00605918 https://hal.science/hal-00605918}

Submitted on 4 Jul 2011

HAL is a multi-disciplinary open access archive for the deposit and dissemination of scientific research documents, whether they are published or not. The documents may come from teaching and research institutions in France or abroad, or from public or private research centers.
L'archive ouverte pluridisciplinaire HAL, est destinée au dépôt et à la diffusion de documents scientifiques de niveau recherche, publiés ou non, émanant des établissements d'enseignement et de recherche français ou étrangers, des laboratoires publics ou privés. 


\title{
Using Equivalent Emission Sources to Evaluate the Coupling between Components
}

\author{
S.Zangui ${ }^{1}$, K.Berger ${ }^{2}$, R.Perrussel ${ }^{1}$, E.Clavel $^{3}$, C.Sartori $^{4}{ }^{\text {and C.Vollaire }}{ }^{1}$ \\ ${ }^{1}$ Laboratoire Ampère - UMR CNRS 5005 \\ Ecole Centrale de Lyon, 36 Avenue Guy de Collongue, 69130 Ecully, France \\ ${ }^{2}$ Groupe de Recherche en Électrotechnique et Électronique de Nancy- EA 4366-France \\ ${ }^{3}$ Laboratoire G2Elab - UMR CNRS 5269- France \\ ${ }^{4}$ Escola Politécnica da Universidade de São Paulo LMAG/PEA/EPUSP- Brasil \\ sanaa.zangui@ec-lyon.fr
}

\begin{abstract}
The electromagnetic interference between the electronic systems or their components influence the performance of the systems. For that reason, it is important to model these interferences in order to optimize the position of the systems or their components. In this paper, a method is proposed to construct the equivalent model of systems. The proposed method is based on the multipolar expansion by representing the radiated emission of generic structures in a spherical reference $(r, \theta, \varphi)$. Some results are presented illustrating our method.
\end{abstract}

\section{INTRODUCTION}

The objective of this work is to propose a methodology suitable for obtaining models that could represent the radiated field of a system or their components, for a wide range of frequencies, useful to evaluate the system performance. These models of sources will be used in a 3D computed code in order to modelize sources, and also to estimate the coupling effects between the systems or system components, basically the mutual inductance, considering the influence of parameters, such as the distance between models.

As the distance between systems is much smaller than the wavelength related to the frequencies of power electronic applications, usually $f<100 \mathrm{MHz}$, a quasi static approach can be considered. It is the case of a magnetic source, in which the capacitive effects are negligible.

The multipolar expansion is proposed to model the radiated field of the systems. It can be used to represent the radiation of generic structures (coils, capacitors, tracks...).

\section{THEORY OF MULTIPOLAR EXPANSION}

The multipolar expansion can be used to represent the electromagnetic fields in $3 \mathrm{D}$, assuming that the field is computed outside a sphere of radius $r$ that contains the equivalent source.

In the case of outgoing radiated emission source, the multipolar expansion allows expressing the electric and magnetic fields as [1]:

$$
\begin{aligned}
\mathbf{E} & =\sum_{n=1}^{\infty} \sum_{m=-n}^{n} Q_{n m}^{T E} \mathbf{F}_{1 n m}(r, \theta, \varphi)+Q_{n m}^{T M} \mathbf{F}_{2 n m}(r, \theta, \varphi) \\
\mathbf{H} & =\frac{\mathrm{j}}{\eta} \sum_{n=1}^{\infty} \sum_{m=-n}^{n} Q_{n m}^{T M} \mathbf{F}_{1 n m}(r, \theta, \varphi)+Q_{n m}^{T E} \mathbf{F}_{2 n m}(r, \theta, \varphi)
\end{aligned}
$$

$-\eta=\sqrt{\frac{\mu}{\varepsilon}}$ is the intrinsic impedance of the considered environment.

- $Q_{n m}^{T E}$ and $Q_{n m}^{T M}$ are the magnetic and electric multipoles, respectively. The coefficients $Q_{\mathrm{nm}}^{T E}$ describe the strength of the transverse-electric (TE) components of the radiated field, while coefficients $Q_{n m}^{T M}$ describe the strength of the transverse-magnetic (TM) components. Each of them corresponds to the equivalent radiated source. Thus, these coefficients are the parameters to be identified to characterize the equivalent model of the radiated field components.

- $\mathbf{F}_{1 n m}$ and $\mathbf{F}_{2 n m}$ are the vector spherical harmonics which are a solution of Maxwell's equations in free space, excluding the sphere that involves the sources.

- $n$ the degree and $m$ the azimuthal order.

In our study, only the magnetic source in the near-field is considered. That is $Q_{n m}^{T M}=0$ and it is assumed that the electric field component is low when compared with the magnetic field. Thus, the determination of the $Q_{n m}^{T E}$ (wrote $Q_{n m}$ in the following) is carried out by the component radial $H_{r}$, in near field [1]:

$$
H_{r}=-\frac{1}{4 \pi} \sum_{n=1}^{+\infty} \sum_{m=-n}^{n} Q_{n m} \frac{\partial}{\partial r}\left(\frac{1}{r^{n+1}}\right) Y_{n m}(\theta, \varphi)
$$

where $Y_{n m}$ are the normalized spherical harmonics

$$
Y_{n m}(\theta, \varphi)=\sqrt{\frac{(2 n+1)(n-m) !}{4 \pi(n+m) !}} P_{n}^{m}(\cos \theta) e^{j m \varphi}
$$

One of the main properties of the multipolar expansion to be emphasized is the decreasing of the order $n$ terms with $r^{n+2}$. This insures a hierarchy between each order of the decomposition. The larger the distance to the source is, the fewer are the terms required to reconstruct the field. In this way, the accuracy of the mutual inductance computation is related with the choice of the maximum order description, noted $N_{\max }$. It should be observed that there are $(2 n+1)$ components for each $n$ order. For an order source equal to $N_{\max }$, it will correspond $N_{\max }\left(N_{\max }+2\right)$ components, but due to the aforementioned property (hierarchy between each order), $N_{\max }$ can be limited, based on the present experience of the authors, up to 5 .

\section{COMPUTING THE MUTUAL INDUCTANCE}

\section{A. Mutual inductance}


Using the equivalent radiated field source model, we can determine the coupling between two equivalent sources through the computation of the mutual inductance. Figure 1 illustrates the configurations regarding the representation of two radiating sources (Models 1 and 2).

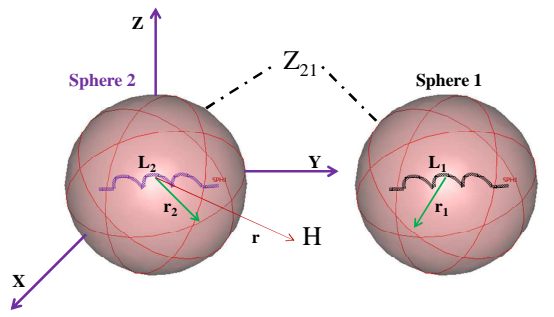

Fig. 1. Representation of two radiating sources

The computation of the mutual impedance between source 1 and source 2 can be expressed in terms of the electrical field $\mathbf{E}$ and magnetic field $\mathbf{H}$ for each source [1]:

$$
Z_{12}=-\frac{1}{i_{1} i_{2}} \oiint_{\Sigma_{1}}\left(\mathbf{E}_{\mathbf{1}} \times \mathbf{H}_{\mathbf{2}}-\mathbf{E}_{\mathbf{2}} \times \mathbf{H}_{\mathbf{1}}\right)
$$

When the spheres which contain each of the sources do not intersect, the mutual impedance can be expressed according to the coefficients of the multipolar expansion:

$$
Z_{12}=\frac{1}{i_{1} i_{2}} \frac{1}{k^{2}} \sqrt{\frac{\varepsilon_{0}}{\mu_{0}}} \sum_{n=1}^{N_{\max }} \sum_{m=-n}^{n}(-1)^{m}\left(Q_{1 n,-m} * Q_{2 n, m}\right)
$$

The expression of the mutual inductance is:

$$
M_{12}=\frac{1}{\mathrm{j} \omega i_{1} i_{2}} \frac{1}{k^{2}} \sqrt{\frac{\varepsilon_{0}}{\mu_{0}}} \sum_{n=1}^{N_{\max }} \sum_{m=-n}^{n}(-1)^{m}\left(Q_{1 n,-m} * Q_{2 n, m}\right)
$$

$i_{1}$ and $i_{2}$ are respectively the current that flows in sources 1 and 2 , and $k$ is the phase constant.

The coefficients associated to the magnetic transverse modes of the multipolar expansion of sources 1 and 2 must be expressed in the same reference: a translation is required, e.g. the coefficients of the source 2 can be expressed in the reference of the source 1 .

\section{B. Translation and rotation of the coefficients $Q_{n m}$}

The rotation of the coefficients $Q_{n m}$ is obtained by applying the Euler angle reference formula. It should be mentioned that only two angles are necessary because of the spherical symmetry. The details of the methodology for determining the rotation matrices for complex or real coefficients $Q_{n m}$ are presented in [2]-[3].

The translation is based on the «Addition Theorem for Vector Spherical Harmonics » [3]. The expression of the translated coefficients $Q^{\prime}{ }_{n m}$ involves the Wigner $3 \mathrm{j}$ symbol according to quantum mechanics [4].

\section{NUMERICAL VALIDATION}

To validate the method of computing the mutual inductance between two equivalent radiated sources of the components, the analytical result was compared to the numerical result computed by Flux ${ }^{\circledR}$ and the analytic result [5]. We consider two loops, $\mathrm{C}_{1}$ and $\mathrm{C}_{2}$ with a radius "Rspire" of $0.1 \mathrm{~m}$, separated by $r$, both located on the Ozaxis as shown in Fig. 2.

To compute the mutual inductance, it is important that the spheres that included each source don't intersect, for that reason a minimum distance equal to $2 *$ Rspire between their center must be respected.

In Fig. 2, the results between the method using a truncated multipolar expansion and the numerical method in Flux ${ }^{\circledR}$ and the analytic method are comparable.

To compute the mutual inductance for a small distance between the two loops, the number of terms required to describe the complexity of the source increases. For that reason, at distance of $r=0.2 \mathrm{~m}$ the error is greater for $n=3$ than $n=5$.

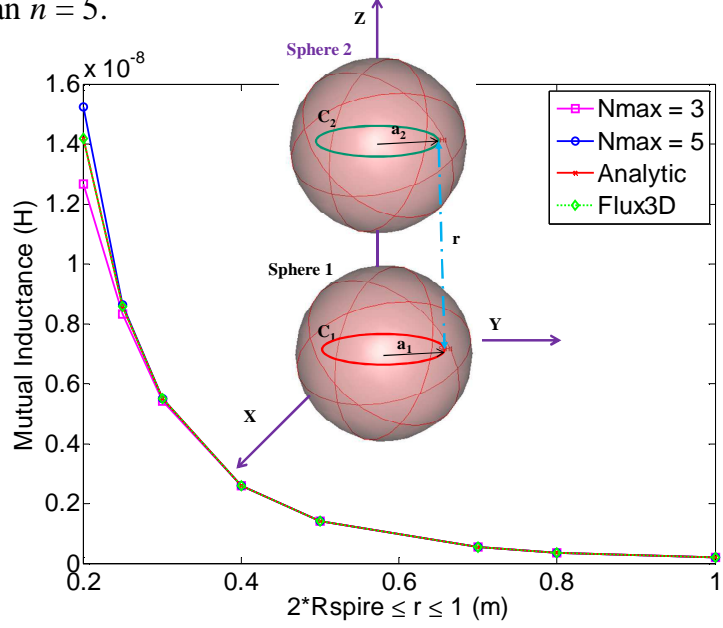

Fig. 2. Comparison between spherical harmonics mutual inductance result and Flux ${ }^{\circledR}$, analytical result up to the near-field distance limit at $200 \mathrm{MHz}$

\section{CONCLUSION}

The presented methodology enables the evaluation of coupling parameters of systems by using equivalent emission sources. This method is composed by two steps. At first, the equivalent sources which represent the radiated field system using the multipolar expansion representation are identified. It can be obtained by a numerical or an experimental approach [6]. Secondly, the equivalent sources will be used to compute the coupling between them, which was represented by a mutual inductance as a function of the distance that separates them. Other cases of validation and the study that computes the mutual inductance when the distance between the sources is very small will be presented in the final paper.

\section{REFERENCES}

[1] Billy C. Brock, "Using vector spherical harmonics to compute antenna mutual impedance from measured or computed fields", SANDIA Report, April 2001.

[2] Miguel A. Blanco et al., "Evaluation of the rotation matrices in the basis of the real spherical harmonics", Journal of Molecular Structure: THEOCHEM, Vol. 419, Issues 1-3, pp. 19-27, Dec. 1997.

[3] Constantine A. Balanis, Advanced Engineering Electromagnetics. John Wiley \& Sons, 1989, Chapter 10, pp. 550-552.

[4] A. Messiah, "Clebsch-Gordan (C.-G.) Coefficients and '3j' Symbols", Appendix C.I in Quantum Mechanics, Vol. 2. Amsterdam, Netherlands: North-Holland, pp. 1054-1060, 1962.

[5] E.Durand, Magnétostatique, Masson et $\mathrm{C}^{\mathrm{ie}}$ Editeurs, 1968, p.175.

[6] B. Vincent et al., "Identification of equivalent multipolar electromagnetic sources by space filtering". IEEE Transactions on Magnetics, Vol. 46 (8), pp. 2815-2818, August 2010. 